\title{
Effects of the External lons and Metabolic Poisoning on the Constriction of the Squid Giant Axon After Axotomy
}

\author{
Paul E. Gallant \\ Laboratory of Neurobiology, National Institute of Neurological and Communicative Disorders and Stroke at the Marine \\ Biological Laboratory, Woods Hole, Massachusetts 02543, and Laboratory of Preclinical Studies, National Institute on \\ Alcohol Abuse and Alcoholism, Rockville, Maryland 20852
}

\begin{abstract}
After transecting the squid giant axon in the presence of an artificial external medium, which was composed of the ions normally present in squid blood, the cut ends of the axon constrict. This constriction could be completely blocked by cutting the axon in the presence of an artificial internal medium composed of the ions normally present inside the axon. By interchanging the ions in the internal medium with those in the external medium, it was determined that constriction was stimulated by the high concentrations of calcium, chloride, and magnesium ions present in the external medium and inhibited by the high concentrations of potassium ion in the internal medium. Constriction could also be inhibited by 2,4-dinitrophenol and cyanide. Softening of axoplasm and elution of the axoplasmic proteins at the cut end of the axon also occurred in the external medium. This softening and elution may be necessary for constriction since constriction occurred only in those media that also induced axoplasmic softening and elution. Softening and elution are not sufficient for constriction, however, since high potassium, 2,4-dinitrophenol, and cyanide inhibited constriction without inhibiting the softening or elution of axoplasm.
\end{abstract}

After transecting an axon, both of its cut ends repair and reseal themselves (Lubinska, 1956; Zelena et al., 1968; Bird, 1978; Meiri et al., 1983; Yawo and Kuno, 1983, 1985). This initial repair requires calcium and involves a number of steps aimed at reestablishing a barrier between the intra- and extracellular compartments. Calcium has been implicated in the reformation of a lipid membrane at a cut end (Yawo and Kuno, 1983, 1985). This may not be the only calcium- or ion-activated process at the exposed end, however, since both the physical properties and chemical state of the cytoplasmic proteins are very sensitive to changes in the ionic environment, especially to changes in calcium ion concentrations (Chambers and Kao, 1952; Schlaepfer, 1971; Gilbert, 1975a, b; Gilbert et al., 1975; Rubinson and Baker, 1979; Schlaepfer and Micko, 1979; Morris and Lasek, 1982). Disassembly and proteolysis of cytoskeletal structures have previously been noted in cut axons and been implicated in Wallerian (Schlaepfer, 1971; Schlaepfer and Micko, 1979) and retrograde (Roederer et al., 1983) degeneration but not in

\footnotetext{
Received Nov. 7, 1986; revised Sept. 25, 1987; accepted Sept. 29, 1987.

I wish to thank Drs. Ichiji Tasaki, Harish Pant, Harold Gainer, and Thomas Reese for their help and support.

Correspondence should be addressed to Paul E. Gallant, Laboratory of Neurobiology, Marine Biological Laboratory, Woods Hole, MA 02543.

0270-6474/88/051479-06\$02.00/0
}

axonal repair (Yawo and Kuno, 1983, 1985). In the present experiments, constriction and closure of the squid giant axon were observed after transection. The dependence of this constriction on the extracellular ions is described, and the relationship between this constriction and softening as well as clution of the axoplasmic proteins is examined. The squid giant axon was used for this study because in this preparation the effects of different test media on the physical (Rubinson and Baker, 1979) and chemical (Gilbert et al., 1975) properties of extruded axoplasm can be measured and compared with the effects of these same media on constriction of the giant axon.

\section{Materials and Methods}

Preparation of axons and solutions. All experiments were performed on axons freshly dissected from squid (Loligo pealei) obtained at the Marine Biological Laboratory, Woods Hole, Massachusetts. The squid were maintained in flowing seawater for up to $20 \mathrm{hr}$ before use. To remove the giant axon from the squid mantles, the mantles were placed on a dissection table supplied with flowing seawater. The axon was then isolated and transferred to a Petri dish containing natural seawater for further cleaning. A binocular microscope was used to visualize the axon while the closely adhering fibers were removed. If the squid muscle showed generalized damage, for example, if the mantle was diffusely white or if the axon showed any signs of stress or injury (white spots or soft axoplasm), the axon was discarded.

After cleaning, the giant axon was equilibrated in a standard externaltype medium consisting of $423 \mathrm{~mm} \mathrm{NaCl}, 9 \mathrm{~mm} \mathrm{KCl}, 9 \mathrm{~mm} \mathrm{CaCl}, 25$ $\mathrm{mM} \mathrm{MgSO}_{4}, 23 \mathrm{~mm} \mathrm{MgCl}_{2}$, and 5-10 mM HEPES ( $N$-2-hydroxyethylpiperazine- $N^{\prime}$-2-ethanesulfonic acid) at $\mathrm{pH} 7.4$ (Table 1). Except for the HEPES, this external solution is similar in ionic composition to squid blood (Gainer et al., 1984) and natural seawater. The standard internaltype medium was composed of $60 \mathrm{mM} \mathrm{NaCl}, 70 \mathrm{mM} \mathrm{KCl}, 100 \mathrm{~mm} \mathrm{~K}$ aspartate, $160 \mathrm{~mm} \mathrm{~K}$ isethionate, $100 \mathrm{~mm}$ taurine, $18 \mathrm{~mm}$ glycine, 75 mM betaine, $10 \mathrm{~mm} \mathrm{MgSO}_{4}$, and $6 \mathrm{mM} \mathrm{K}^{+}$-HEPES, pH 7.4 (Morris and Lasek, 1982; see Table 1). This internal medium contains the major ions present in fresh axoplasm. The standard internal-type medium was isotonic with the standard external-type medium, and all substitutions to either media were made isotonically.

Measuring axonal constriction. After equilibrating the axon in a given test medium for 10-20 min, the axon was transferred to fresh medium. The inside diameter of each axon was measured with the aid of a 30 80 power dissection microscope equipped with a filar micrometer eyepiece. Illumination was by bright-field, reflected light. Minimum diameters at the cut end were measured 5, 15, 60, and 100 min after cutting the giant axon with a pair of Castroviejo ultra micro dissecting scissors. Axons were photographed through a Zeiss binocular microscope with dark-field illumination seconds after, 5 min after, and 100 min after transection.

Measuring stiffness and protein composition of axoplasm. To study the effects of various media on axoplasm, the axoplasm was extruded from the giant axon and incubated for up to $30 \mathrm{~min}$ in various media. Stiffness was then assayed by measuring the ability of the extruded axoplasm to resist flow and uptake into one of a series of test capillary tubes under the force of capillary pressure plus the $5 \mathrm{~mm}$ of hydrostatic 

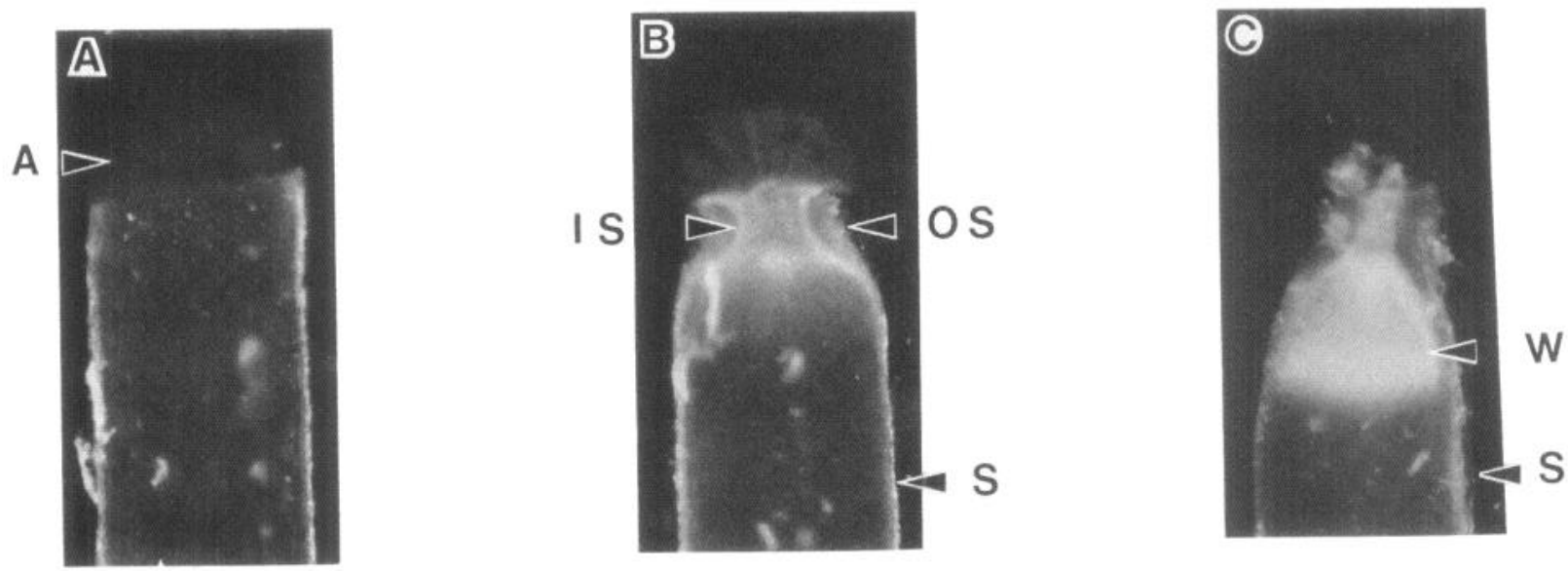

Figure 1. Constriction and closure of the squid giant axon after transection. The axon was cleaned, placed in the standard external medium, and photographed: $A$, several seconds after; $B, 5 \mathrm{~min}$ after; and $C, 100 \mathrm{~min}$ after transecting the axon with a pair of micro dissection scissors. The sheath $(S)$ surrounding the axon split into an inner sheath $(I S)$ and an outer sheath $(O S)$ at the site of constriction. Axoplasm $(A)$ began to bulge out of the cut end after transection, and the cut end began to turn white $(W)$ with time.

pressure produced by the overlaying test solution. This force was exerted on the axoplasm by blocking one end of a capillary tube and lowering the open end into the test solution until it came into direct contact with the extruded axoplasm. The blocked end was then released, and the axoplasm was forced against the opening of the tube by the hydrostatic pressure of the overlaying solution. Stiff axoplasm would resist entry into the tube, while soft axoplasm would be rapidly taken in. The micro capillary tubes were 840,540 , and $360 \mu \mathrm{m}$ in diameter. The stiffness scores ranged from 0 to 4 , with the stiffest axoplasms receiving the highest scores. If the axoplasm collapsed or flattened out under its own weight, it received a score of 0 ; if the axoplasm was not collapsed but could be deformed and taken up into a $360 \mu \mathrm{m}$ tube, it received a score of 1; axoplasm received a score of 2, 3, or 4 if it failed to enter the 360 , 540 , or $840 \mu \mathrm{m}$ capillary tubes, respectively. To measure the ability of the various media to elute proteins out of axoplasm, a sample of extruded axoplasm was incubated in the test media for $30 \mathrm{~min}$ and then spun down at $48,000 \times g$ for $10 \mathrm{~min}$. The axoplasmic pellet was recovered and dissolved in an SDS buffer (composed of $2 \%$ SDS, $5 \%$ $\beta$-mercaptoethanol, and $100 \mathrm{~mm}$ Tris sulfate at $\mathrm{pH} 7.0$ ). The pelleted axoplasmic proteins were then separated on a $7 \frac{1}{2} \%$ polyacrylamide slab gel (Neville, 1971), stained with Coomassie Brilliant blue R-250, and photographed or scanned with an Ortec optical density scanner.

\section{Results}

\section{Constriction of axons transected in the presence of different media}

Figure 1 illustrates the appearance of a typical axon seconds after $(1 A), 5 \mathrm{~min}$ after $(1 B)$, and $100 \mathrm{~min}$ after $(1 C)$ transection in the presence of the standard external medium (see Table 1). After cleaning the axon, the glial sheath and connective tissue layer surrounding the giant axon was seen as a bright line surrounding the axon. Some of the connective tissue can also be seen on the surface of the axon. Immediately after cutting the axon, a small amount of stiff axoplasm begins to bulge out, forming a translucent layer that protrudes from the rim of the cut axon (Fig. 1A). By 5 min after transection the exposed axoplasm had softened considerably, and a narrowing or constriction (Fig. 1B) formed a short distance from the cut end. A thin inner sheath can be distinguished from a diffuse outer one in this constricted area. By $100 \mathrm{~min}$ after transection the inner sheaths have almost completely closed down. By this time the cut end had become opaque (Fig. 1C), and the axoplasm that originally bulged out of the axon had been eluted into the surrounding medium.

The rate of constriction was determined by measuring the distance between the inner sheaths at 5, 15, 30, 60, and 120 min after transection (Fig. 2). Constriction was rapid during the first $15 \mathrm{~min}$, slower during the next $45 \mathrm{~min}$, and had usually stopped by 60 min after transection (Fig. 2). Most ( $98 \%$ ) of the transected axons closed to about $6 \%$ of their original diameter (i.e., to about $1 \%$ of their calculated cross-sectional area) by 60 $120 \mathrm{~min}$ after transection. These axons remained closed for at least $12 \mathrm{hr}$ after transection, and all the constricted axons tested $(8 / 8)$ conducted action potentials to within millimeters of the constricted end.

The reaction of the axon to transection was apparently due to the sudden exposure of the cut end to at least some of the external ions since neither constriction nor axoplasmic whitening occurred when axons were cut in the presence of the standard internal medium (Fig. 2, dotted line), which consisted of the major ions normally present inside the axon (Table 1; Morris and Lasek, 1982).

To determine if the presence of any one of the external ions was sufficient to stimulate constriction when added to the in-

Table 1. Composition of the standard external and internal media

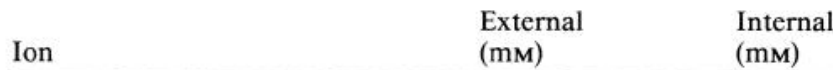

Monovalent cations

$\mathrm{Na}^{+}-423 \quad 60$

$\mathrm{K}^{+}$

Monovalent anions

$\mathrm{Cl}^{-}$

496

130

Isethionate

0

Aspartate-

0

160

Amines

Taurine

Betaine

Glycine

0

Divalent

100

$\mathrm{Mg}^{2+}$

$\mathrm{Ca}^{2+}$

48

9

10

Divalent anion

$\mathrm{So}_{4}{ }^{2-}$

25 


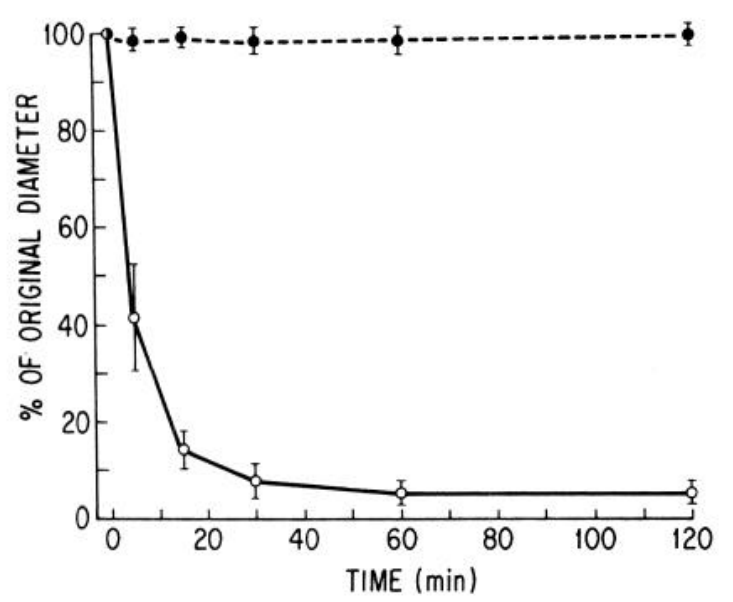

Figure 2. Time course of constriction at the cut ends of the squid giant axon. The original inside diameter of each axon was taken as control $(100 \%)$, and the subsequent minimum distances between the 2 inner sheaths at the cut ends were measured. Data are expressed as mean \pm SD. The number of experiments $(n)$ equals 24 for external medium (solid line) and 12 for the standard internal medium (dotted line).

ternal medium, the major external ions were added, one at a time to the internal medium. While the addition of $\mathrm{Na}^{+}, \mathrm{Mg}^{2+}$, $\mathrm{Cl}^{-}\left(+\mathrm{Na}^{+},+\mathrm{Mg}^{2+}\right.$, or $+\mathrm{Cl}^{-}$, Table 2 , column 3$)$, or $\mathrm{SO}_{4}{ }^{2-}$ (not illustrated) had no significant effect on constriction, the addition of $9 \mathrm{mM} \mathrm{Ca}^{2+}$ to the internal medium caused the axon to constrict to $21 \%$ of its original diameter (Table $2,+9 \mathrm{mM} \mathrm{Ca}^{2+}$ ).

To determine if any of the external ions were essential to the constriction that occurred in the external media, each of these ions was reduced to its internal level (see Table 1). Neither $\mathrm{Na}^{+}$, $\mathrm{Mg}^{2+}$, or $\mathrm{Cl}^{-}$was necessary for constriction since each could be reduced to the internal level individually or in combination (Table 2: $-\mathrm{Na}^{+} /+\mathrm{Tris}^{+},-\mathrm{Mg}^{2+},-\mathrm{Cl}^{-}$, or $-\mathrm{Mg}^{2+}-\mathrm{Cl}^{-}$) without affecting constriction. $\left[\mathrm{Na}^{+}\right.$was replaced with $\mathrm{Tris}^{+}$(tris(hydroxymethyl)aminoethane), $\mathrm{Mg}^{2+}$ with $\mathrm{Na}^{+}$, and $\mathrm{Cl}^{-}$with isethionate.] $\mathrm{Ca}^{2+}$ was essential to constriction, however, since reducing this ion to $0.1 \mathrm{~mm}$ (not shown) or removing it completely from the external medium (Table 2, $-\mathrm{Ca}^{2+}$ ) inhibited constriction to $55 \%$ of the original diameter. Reducing $\mathrm{Ca}^{2+}$ plus $\mathrm{Mg}^{2+}, \mathrm{Ca}^{2+}$ plus $\mathrm{Cl}^{-}$, or all 3 of these ions $\left(\mathrm{Ca}^{2+}, \mathrm{Mg}^{2+}\right.$, and $\left.\mathrm{Cl}^{-}\right)$ inhibited constriction completely. Though $\mathrm{Na}^{+}$was not essential to constriction (since it could be completely replaced by Tris $^{+}$ without inhibiting constriction, as noted above), replacing all (432 mM) or most $(370 \mathrm{~mm})$ of the $\mathrm{Na}^{+}$with $\mathrm{K}^{+}$significantly inhibited constriction (Table $2,-\mathrm{Na}^{+} /+\mathrm{K}^{+}$).

\section{Collapse of the axon in the presence of metabolic poisons or high $\mathrm{K}^{+}$}

Adding either $1 \mathrm{~mm}$ 2,4-dinitrophenol (DNP) or $2 \mathrm{~mm}$ sodium cyanide to the external medium inhibited more than half of the constriction normally present in the external medium (Tables 2 and 3 ). These metabolic poisons not only inhibited constriction but also allowed the axoplasm to continue to soften and flow out of the axon until the whole axon collapsed (Table 3 ). Incubating the axon in the presence of an external medium containing high $\mathrm{K}^{+}$levels also led to significant, though less extensive, collapse of the opened ends (Table 3), so that by 12 hr 2-4 mm of axon had collapsed at each end. This collapse was apparently due to the continued exposure of the unconstricted end to one or more of the external ions since the axon

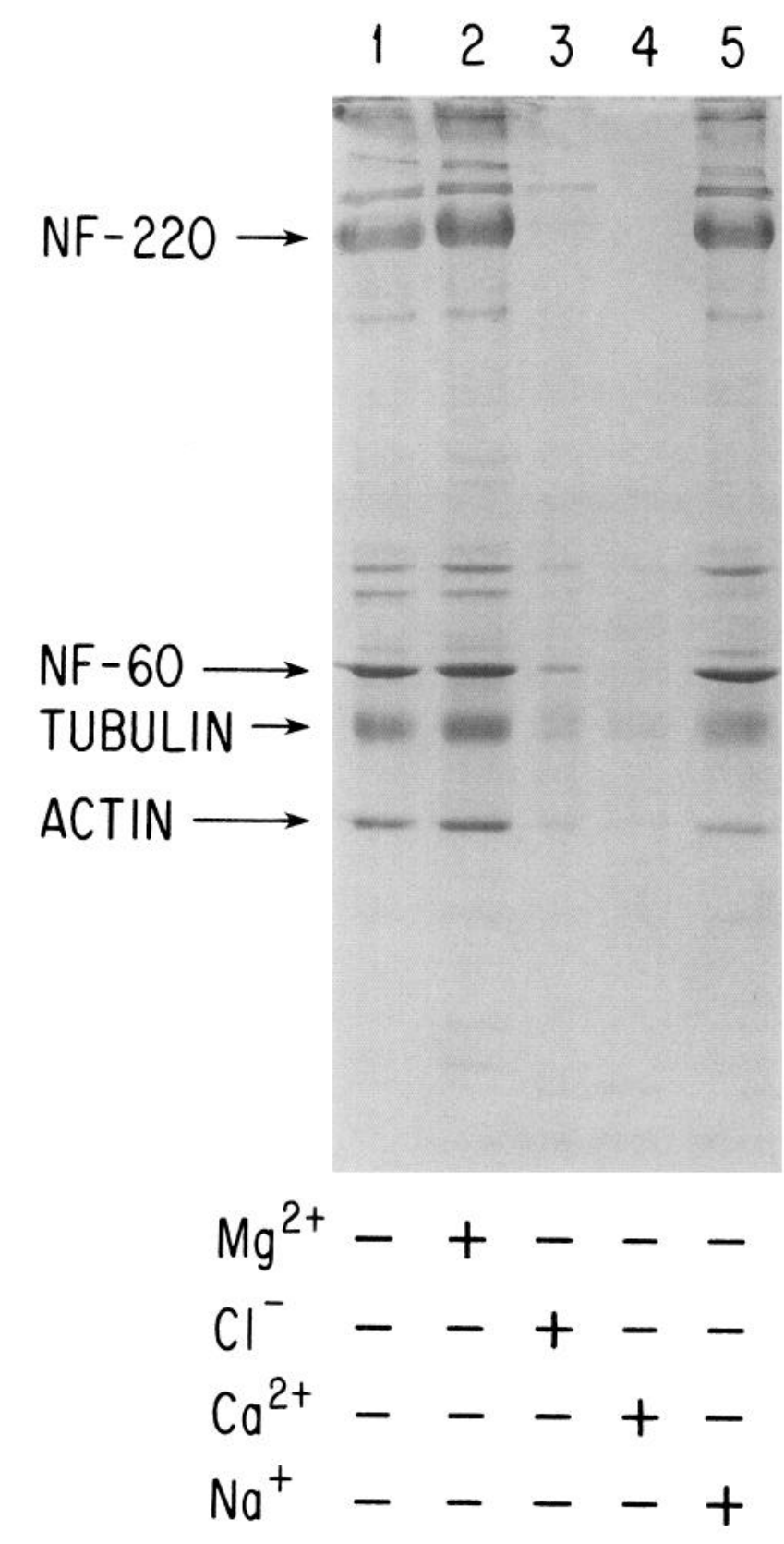

Figure 3. Coomassie Blue staining pattern of the axoplasmic proteins separated by SDS-PAGE after a 30 min incubation in the presence of one of the experimental media. NF-220 and NF-60 represent neurofilament polypeptides that migrate at 220 and $60 \mathrm{kDa}$, respectively, on the SDS-PAGE. Actin and tubulin are also indicated. Axoplasm was incubated in an external- or internal-type medium. The axoplasm was then pelleted, dissolved in SDS and separated by SDS-PAGE. The first lane is the staining pattern of the proteins that remain pelletable after incubating axoplasm in the standard internal medium. In lanes $2-4$, the $\mathrm{Mg}^{2+}, \mathrm{Cl}^{-}$, or $\mathrm{Ca}^{2+}$ ions were raised to the external levels $(+)$ or remained at the internal levels (-) as indicated. Otherwise, the media in lanes 24 were the same as the normal internal medium $\left[\mathrm{Mg}^{2+}\right.$ and $\mathrm{Ca}^{2+}$ were exchanged with $\mathrm{K}$, while $\mathrm{Cl}^{-}$was exchanged with the monovalent anions and amines of the internal medium (Table 1)]. The medium used in lane 5 was produced by lowering the $\mathrm{Mg}^{2+}, \mathrm{Cl}^{-}$, and $\mathrm{Ca}^{2+}$ present in the normal external medium to internal $(-)$ levels. $\mathrm{Na}^{+}$remained at external levels, while most $(366 \mathrm{~mm})$ of the $\mathrm{Cl}^{-}$was replaced with isethionate; $38 \mathrm{mM} \mathrm{Mg}^{2+}$ and all the $\mathrm{Ca}^{2+}$ was replaced with $\mathrm{Na}^{+}$. See Table 1 for external and internal concentrations of each ion. 
Table 2. Effects of various media on axoplasmic elution and stiffness, and axonal constriction

\begin{tabular}{|c|c|c|c|}
\hline & $\begin{array}{l}\text { Elution: } \\
\text { \% Cytoskeletal } \\
\text { proteins remaining }\end{array}$ & $\begin{array}{l}\text { Stiffness: } \\
\text { Axoplasmic } \\
\text { stiffness }\end{array}$ & $\begin{array}{l}\text { Constriction: } \\
\% \text { Original } \\
\text { axonal } \\
\text { diameter }\end{array}$ \\
\hline \multicolumn{4}{|l|}{ Internal-type media } \\
\hline Standard internal & $100 \pm 7$ & $3.8 \pm 0.5$ & $98 \pm 3.3$ \\
\hline$+392 \mathrm{Na}$ & $100 \pm 8$ & $3.8 \pm 0.7$ & $97 \pm 5$ \\
\hline$+48 \mathrm{mM} \mathrm{Mg}^{2+}$ & $95 \pm 10$ & $3.7 \pm 0.5$ & $97 \pm 2.5$ \\
\hline$+490 \mathrm{mM} \mathrm{Cl}^{-}$ & $26+4 \dagger$ & $1.5+0.5 \dagger$ & $91 \pm 9.0$ \\
\hline$+9 \mathrm{mM} \mathrm{Ca}^{2+}$ & $20 \pm 3 \dagger$ & $0.5 \pm 0.5 \dagger$ & $21 \pm 3.3 \dagger$ \\
\hline \multicolumn{4}{|l|}{ External-type media } \\
\hline$-\mathrm{Ca}^{2+}-\mathrm{Cl}^{-}-\mathrm{Mg}^{2+}$ & $95 \pm 15^{*}$ & $3.9 \pm 0.4^{*}$ & $98 \pm 4^{*}$ \\
\hline$-\mathrm{Ca}^{2+}-\mathrm{Cl}^{-}$ & $40 \pm 20^{*}$ & $3.0 \pm 0.4^{*}$ & $98 \pm 8^{*}$ \\
\hline$-\mathrm{Ca}^{2+}-\mathrm{Mg}^{2+}$ & $30 \pm 20^{*}$ & $2.0 \pm 1.0^{*}$ & $98 \pm 4.0^{*}$ \\
\hline$-\mathrm{Ca}^{2+}+10 \mathrm{mM} \mathrm{Mg}{ }^{2+}$ & $30 \pm 15^{*}$ & $1.2 \pm 0.4^{*}$ & $98 \pm 3.2^{*}$ \\
\hline$-\mathrm{Ca}^{2+}$ & $28 \pm 8^{*}$ & $1.0 \pm 0^{*}$ & $55 \pm 6.2^{*}$ \\
\hline$-\mathrm{Mg}^{2+}-\mathrm{Cl}^{-}$ & $12 \pm 3$ & $0.0 \pm 0$ & $7 \pm 2$ \\
\hline$-\mathrm{Cl}^{-}$ & $13 \pm 5$ & $0.0 \pm 0$ & $7 \pm 3$ \\
\hline$-\mathrm{Mg}^{2+}$ & $13 \pm 8$ & $0.0 \pm 0$ & $8 \pm 3$ \\
\hline$-\mathrm{Na}^{+} /+432 \mathrm{~mm}$ Tris $^{+}$ & $12 \pm 8$ & $0.0 \pm 0$ & $6 \pm 4$ \\
\hline Standard external & $12 \pm 4$ & $0.0 \pm 0$ & $6 \pm 2.5$ \\
\hline$+1.0 \mathrm{~mm}$ DNP & $14 \pm 6$ & $0.0 \pm 0$ & $63 \pm 30^{*}$ \\
\hline$+2.0 \mathrm{~mm}$ cyanide & $12 \pm 5$ & $0.0 \pm 0$ & $62 \pm 10^{*}$ \\
\hline$-\mathrm{Na}^{+} /+432 \mathrm{~mm} \mathrm{~K}^{+}$ & $11 \pm 3$ & $0.0 \pm 0$ & $58 \pm 9^{*}$ \\
\hline$-\mathrm{Na}^{+} /+370 \mathrm{~mm} \mathrm{~K}{ }^{+}$ & $12 \pm 4$ & $0.0 \pm 0$ & $21 \pm 6^{*}$ \\
\hline
\end{tabular}

In the first column (elution) the percentage of cytoskeletal proteins remaining represents the amount of protein left in the axoplasmic pellet after a $30 \mathrm{~min}$ incubation in the test medium. Protein content was measured by integrating the total staining density from each eluted and electrophoresed sample. The recovery in each medium was compared (as a percentage) to the proteins recovered in the internal medium. Each medium used was either a modified internal (first 5) or a modified external-type medium (all others). Changes were made by increasing ions to their external levels $(+)$ or decreasing them to internal ( -$)$ levels as indicated. Each value in the first column of this figure represents the average of 4-8 such experiments. Stiffness (second column) was determined by testing the ability of the incubated axoplasm to resist deformation and entry into a capillary tube. A score of 4 represents the stiffest axoplasm and 0 the softest (see Materials and Methods for a description of the stiffness assay). Each mean is the average of 4-12 stiffness experiments. Constriction (percentage original diameter, third column) was measured by determining the distance between the inner sheaths of an axon before and $60 \mathrm{~min}$ after transection in the presence of the test medium. Note that the minimal amount of constriction, softening, and elution occurred in the presence of standard internal medium and maximal changes occurred in the presence of the standard external medium. For maximal inhibition of the softening and elution present in the standard external medium $\mathrm{Ca}^{2+}, \mathrm{Cl}^{-}$, and $\mathrm{Mg}^{2+}$ had to be reduced. The asterisk indicates a value significantly different from the standard external control $(p<0.01)$, and the dagger indicates a value significantly different from the standard internal control $(p<0.01)$ by student $t$ test.

did not collapse when they were cut in the presence of the internal medium, nor did collapse occur when the cut ends constricted, i.e., in the presence of the external medium (Table 3).

\section{Effects of different ions and metabolic poisons on the stiffness of axoplasm}

Freshly extruded axoplasm is a viscous gel with a high resistance to flow and mechanical deformation (Rubinson and Baker, 1979). This stiffness is rapidly lost, however, after exposing the axoplasm to external medium. To determine which external ions promote softening of axoplasm, the stiffness of extruded axoplasm was measured in the presence of the different internal and external type media. Stiffness of extruded axoplasm was measured by attempting to pull extruded axoplasm into different sized capillary tubes under the force of the $5 \mathrm{~mm}$ of hydrostatic pressure exerted by the overlying solution. The stiffest axoplasm received a score of 4 , while the softest received a score of 0 .

Normally, axoplasm is stiff and cannot be taken up into a capillary tube ( $840 \mu \mathrm{m}$ diameter). This normal stiffness is retained for hours if the axoplasm is extruded into standard internal medium (Table 2, Stiffness). Neither $\mathrm{Mg}^{2+}$ nor $\mathrm{Na}^{+}$sig-
Table 3. Inhibitors of constriction

\begin{tabular}{llc} 
& $\begin{array}{l}\text { Constriction } \\
\text { (\% original } \\
\text { diameter) }\end{array}$ & $\begin{array}{l}\text { Length of } \\
\text { collapsed } \\
\text { axon }(\mathrm{mm})\end{array}$ \\
\hline Dinitrophenol $(1.0 \mathrm{mM})$ & $63.0 \pm 30$ & $5.0 \pm 0^{*}$ \\
Sodium cyanide $(2.0 \mathrm{mM})$ & $62.0 \pm 10$ & $5.0 \pm 0^{*}$ \\
$\mathrm{~K}^{+}(432 \mathrm{mM})$ external & $58.0 \pm 9$ & $3.6 \pm 1.3$ \\
External & $6.2 \pm 2.5$ & $0.72 \pm 0.5$
\end{tabular}

Axons were preincubated for $30 \mathrm{~min}$ in the presence of the standard external medium with or without high dinitrophenol (DNP), potassium $\left(\mathrm{K}^{+}\right)$, or sodium cyanide $\left(\mathrm{CN}^{-}\right)$. A $1 \mathrm{~cm}$ length was then cut from each axon and observed at 2 and $12 \mathrm{hr}$ after cutting. For these long-term experiments, ampicilin $(10 \mu \mathrm{g} / \mathrm{ml})$, streptomycin $(100 \mu \mathrm{g} / \mathrm{ml})$, and dextrose $(1 \mathrm{mg} / \mathrm{ml})$ were added to each solution. $\mathrm{K}^{+}$external medium was made by replacing the $\mathrm{Na}^{+}$normally present in the external medium with $\mathrm{K}^{+}$(see Table 1). Constriction was determined as before, by measuring the distance between the 2 inner sheaths. The length of collapsed axon was measured from the cut end inward. If the whole axon* $(10 \mathrm{~mm})$ collapsed, the length of collapse was taken as $5 \mathrm{~mm}$ (from cach cnd). Axons cut in external medium constricted and stabilized within the first $2 \mathrm{hr}$. $\mathrm{K}^{+}$, DNP-, and $\mathrm{CN}^{-}-$ treated axons, however, continued to remain open and continued to collapse. Means are the average of $4-8$ experiments for $\mathrm{DNP}, \mathrm{CN}^{-}$, and $\mathrm{K}^{+}$and 24 experiments for the normal external medium. 
nificantly reduced this stiffness. Adding $\mathrm{Cl}^{-}$to the internal medium significantly softened axoplasm, however, and adding $\mathrm{Ca}^{2+}$ softened axoplasm even more (Table 2).

Incubating axoplasm in the external medium led to the most rapid softening of axoplasm. This softening was not affected by reducing $\mathrm{Cl}^{-}, \mathrm{Mg}^{2+}$, or $\mathrm{Na}^{+}$to the levels present in the internal medium. Softening could be partially inhibited, however, by reducing $\mathrm{Ca}^{2+}$ and was inhibited even more if $\mathrm{Ca}^{2+}$ and $\mathrm{Cl}^{-}$or $\mathrm{Ca}^{2+}$ and $\mathrm{Mg}^{2+}$ were reduced. Total inhibition of axoplasmic softening in the external media required the reduction of all 3 of these ions to their internal levels $\left(-\mathrm{Ca}^{2+}-\mathrm{Cl}^{-}-\mathrm{Mg}^{2+}\right.$, Table 2). Though DNP, cyanide and high $\mathrm{K}^{+}$significantly inhibited constriction, these agents had no effect on axoplasmic softening (Table 2).

\section{Effects of ions and metabolic poisons on the elution of axoplasmic proteins}

To measure the effects of the various internal and external ions and metabolic poisons on the elution of axoplasmic proteins extruded axoplasm was exposed to these different media for 30 min and then spun down at $48,000 \times g$. The axoplasmic pellet was then recovered and analyzed by SDS-PAGE. These experiments demonstrated that the same solutions and ions that promoted axoplasmic softening also promoted the elution of the axoplasmic proteins.

Incubating axoplasm in the standard internal-type medium eluted some of the proteins out of the axoplasm (not shown, but see Morris and Lasek, 1982, 1984) but left behind many of the cytoskeletal proteins, including most of the neurofilament polypeptides and a significant amount of tubulin and actin (Fig. 3, lane 1). Addition of $\mathrm{Mg}^{2+}$ to the internal medium had no significant effect on the total amount of protein eluted from axoplasm (Fig. 3, lane 2, and Table 2, Elution). Addition of $\mathrm{Cl}^{-}$ or $\mathrm{Ca}^{2+}$ to the internal medium, however, led to elution of 74 and $80 \%$ of these proteins from axoplasm, respectively (Fig. 3, lanes 3 and 4 , and Table 2).

Incubating axoplasm in the standard external medium led to the largest loss of the axoplasmic proteins (Table 2, Elution, Standard External). This loss of the axoplasmic proteins was not inhibited by reducing $\mathrm{Na}^{+}, \mathrm{Mg}^{2+}, \mathrm{Cl}^{-}$, or both $\mathrm{Mg}^{2+}$ and $\mathrm{Cl}^{-}$ to internal levels (Table 2). However, reducing $\mathrm{Ca}^{2+}$, did inhibit the loss of some of the cytoplasmic proteins (Table 2 ). In order to inhibit protein loss maximally $\mathrm{Ca}^{2+}, \mathrm{Cl}^{-}$, and $\mathrm{Mg}^{2+}$ had to be reduced from external to internal levels (Fig. 3, lane 5, and Table 2). Osmolarity was maintained in these experiments by replacing $\mathrm{Cl}^{-}$with isethionate (the major internal anion), while $\mathrm{Ca}^{2+}$ and $\mathrm{Mg}^{2+}$ were replaced with $\mathrm{Na}^{+}$. As was the case for softening, neither DNP, cyanide, or $\mathrm{K}^{+}$had any effect on the elution of the cytoskeletal proteins from the axoplasmic pellet (Table 2).

\section{Discussion}

Young $(1935,1937)$ observed that after transecting the giant axon of Sepia officianalis in the presence of seawater the sheath began to constrict. Conditions were apparently unsuitable for the completion of constriction in these early experiments, however, since axoplasm continued to flow out of the axon until the axon collapsed. A similar observation was made on the giant axon from Loligo. Cutting this axon usually led to the continuous outflow of axoplasm (Flaig, 1947). A few of the Loligo axons, however, did remain "plugged" and retained their axoplasm. In the present experiments, it was determined that when a metabolically intact squid giant axon was transected in the presence of an artificial squid blood (external medium) the cut end constricted and the axon retained its axoplasm for hours after transection.

The ability of the squid giant axon to close up and retain its axoplasm after transection is in agreement with the findings in a number of mammalian axons and an arthropod (cockroach) axon, in which axoplasm does not continue to flow out after transection (Serini and Young, 1932; Zelena et al., 1968; Friede and Martinez, 1970; Bird, 1978; Sole, 1980; Gross et al., 1983). After cutting, these axons close up (Zelena et al., 1968) and reform a high-resistance seal (Meiri et al., 1981; Gross et al., 1983; Yawo and Kuno, 1983).

To determine exactly which of the ions in the external medium were responsible for constriction of the squid giant axon as well as elution of cytoplasmic proteins and softening of axoplasm, each of the ions in the external medium was replaced by its counterpart in the internal medium, and vice versa. These experiments support the idea that axonal constriction and axoplasmic softening and elution are all stimulated by the high concentrations of $\mathrm{Ca}^{2+}, \mathrm{Cl}^{-}$, and $\mathrm{Mg}^{2+}$ present in the external medium. Of these ions, $\mathrm{Ca}^{2+}$ was the most effective stimulator of constriction, softening, and elution. $\mathrm{Ca}^{2+}$ was not the only external ion that stimulated constriction softening and elution, however, since even in the absence of $\mathrm{Ca}^{2+}$ the axon constricted to about $55 \%$ of its original diameter and the axoplasm was significantly softened and eluted. In order to completely inhibit constriction $\mathrm{Ca}^{2+}$ and at lcast one of the other constrictive ions $\left(\mathrm{Cl}^{-}\right.$or $\left.\mathrm{Mg}^{2+}\right)$ had to be reduced to internal levels, and in order to completely inhibit elution and softening all 3 of these ions $\left(\mathrm{Ca}^{2+}, \mathrm{Cl}^{-}\right.$, and $\left.\mathrm{Mg}^{2+}\right)$ had to be reduced. $\mathrm{K}^{+}$also had an effect on constriction, but unlike $\mathrm{Ca}^{2+}, \mathrm{Cl}^{-}$, and $\mathrm{Mg}^{2+}$, the presence of $\mathrm{K}^{+}$inhibited, rather than stimulated, constriction and $\mathrm{K}^{+}$had no effect on axoplasmic softening or elution. Though the means

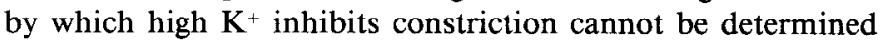
based on the present experiments, this action might be related to ability of high concentrations of external $\mathrm{K}^{+}$to inhibit the injury current generated at a cut end since this injury current is thought to affect the resealing of severed axons (Roederer et al., 1983).

The present results suggest that softening and elution may be necessary for constriction since partial constriction required at least partial softening and elution, while maximal constriction required maximal softening and elution. Elution and softening were not sufficient for constriction, however, since $\mathrm{K}^{+}$, DNP, and sodium cyanide could inhibit constriction without inhibiting softening or elution.

Other factors, in addition to softening of axoplasm, are thus required for successful constriction. Though softening might be expected to remove the axoplasm's resistance to constriction, some force must also be exerted on or by the inner sheath in order to draw this sheath in and close off the axon. The source of this force is unknown. ATP might be a source for at least some of the energy required for constriction since 2,4-DNP and cyanide, which lower ATP levels in the squid giant axon (Caldwell, 1960), significantly inhibited constriction.

Whatever the mechanism used for constriction, the closing off of the axon after transection may serve to protect the axon from further injury. This is suggested by the observation that axoplasm is retained, and the axon appears normal for hours after a successful constriction. When the axon fails to constrict, however, the cut end of the axon continues to be exposed to the external ions and the axoplasm continues to be denatured and 
eluted. Thus, while uncontrolled entry of the extracellular ions into an axon might lead to retrograde (Roederer et al., 1983) and Wallerian (Schlaepfer, 1971) degeneration, limited entry of these same ions into the cut ends may be essential to the localized resealing of an axon after transection.

\section{References}

Bird, M. M. (1978) Microsurgical transection of small nerve fiber bundles in vitro. Cell Tissue Res. 190: 525-538.

Caldwell, P. C. (1960) The phosphorus metabolism of squid axons and its relationship to the active transport of sodium. J. Physiol. (Lond.) 152: 545-560.

Chambers, R., and C. Kao (1952) The effects of electrolytes on the physical state of the nerve axon of the squid and of the stentor and protozoon. Exp. Cell Res. 3: 564-573.

Flaig, J. V. (1947) Viscosity changes in axoplasm under stimulation. J. Neurophysiol. 10: 211-221.

Friede, R. L., and A. J. Martinez (1970) Analysis of the process of sheath expansion in swollen nerve fibers. Brain Res. 19: 165-182.

Gainer, H., P. E. Gallant, R. Gould, and H. C. Pant (1984) Biochemistry and metabolism of the squid giant axon. In Current Topics in Membranes and Transport: The Squid Giant Axon, P. F. Baker, ed., pp. 58-81, Academic, Orlando, FL.

Gilbert, D. S. (1975a) Axoplasm chemical composition in myxicola and solubility properties of its structural proteins. J. Physiol. (Lond.) 253: 303-319.

Gilbert, D. S. (1975b) Axoplasm architecture and physical properties as seen in the myxicola giant axon. J. Physiol. (Lond.) 253: 257-301.

Gilbert, D. S., B. J. Newby, and B. H. Anderton (1975) Neurofilament disguise, destruction and discipline. Nature 256: 586-589.

Gross, G. W., J. H. Lucas, and M. L. Higgins (1983) Laser microbeam surgery: Ultrastructural changes associated with neurite transection in culture. J. Neurosci. 3: 1979-1993.

Lubinska, L. (1956) Outflow from cut ends of nerve fibers. Exp. Cell Res. 10: 40-47.

Meiri, H., M. E. Spira, and I. Parnas (1981) Membrane conductance and action potential of a regenerating axonal tip. Science $211: 709-$ 712 .

Meiri, H., A. Dormann, and M. E. Spira (1983) Comparison of ul- trastructural changes in proximal and distal segments of transection giant fibers of the cockroach Perialaneta americana. Brain Res. 263 $1-14$.

Morris, J. R., and R. J. Lasek (1982) Stable polymers of the axonal cytoskeleton: The axoplasmic ghost. J. Cell Biol. 92: 192-198.

Morris, J. R., and R. J. Lasek (1984) Monomer-polymer equilibrium in the axon: Direct measurement of tubulin and actin as polymer and monomer in axoplasm. J. Cell Biol. 98: 2064-2076.

Neville, D. (1971) Molecular weight determination of protein-dodecyl sulfate complexes by gel electrophoresis in a discontinuous buffer system. J. Biol. Chem. 246: 6328-6334.

Roederer, E., N. H. Goldberg, and M. J. Cohen (1983) Modification of retrograde degeneration in transected spinal axons of the lamprey by applied DC current. J. Neurosci 3: 153-160.

Rubinson, K. A., and P. F. Baker (1979) The flow properties of axoplasm in a defined chemical environment: Influcnce of anions and calcium. Proc. R. Soc. Lond. [Biol.] 205: 323-345.

Schlaepfer, W. W. (1971) Experimental alterations of neurofilaments and neurotubules by calcium and other ions. Exp. Cell Res. 67: 7380 .

Schlaepfer, W. W., and S. Micko (1979) Calcium-dependent alterations of neurotilament proteins of rat peripheral nerve. J. Neurochem. 32: 211-219.

Sereni, E., and J. Z. Young (1932) Nervous degeneration and regeneration in cephalopods. Pubbl. Staz. Zool. Napoli 12: 173-208.

Sole, G. M. (1980) The effects of microsurgical transection of neurite bundles in vitro before and after exposure to colchicine. J. Anat. 130 777-788

Yawo, H., and M. Kuno (1983) How a nerve repairs its cut end: Involvement of phospholipase A2. Science 222: 1351-1353.

Yawo, H., and M. Kuno (1985) Calcium dependence of membrane sealing at the cut end of the cockroach giant axon. J. Neurosci. 5 : 1626-1632.

Young, J. Z. (1935) Structure of nerve fibers in sepia. J. Physiol. (Lond.) 83: 27P.

Young, J. Z. (1937) The structure of nerve fibers in cephalopods and crustacea. Proc. R. Soc. Lond. [Biol.] 121: 319.

Zelena, J., L. Lubinska, and E. Gutman (1968) Accumulation of organelles at the ends of interrupted axons. Z. Zellforsch Microsk. Anat 91: 200-219. 